\title{
Non-Cell-Autonomous Photoreceptor Degeneration in rds Mutant Mice Mosaic for Expression of a Rescue Transgene
}

\author{
Wojciech Kedzierski, ${ }^{1}$ Dean Bok, ${ }^{2}$ and Gabriel H. Travis ${ }^{1}$ \\ ${ }^{1}$ Department of Psychiatry and Program in Neuroscience, University of Texas Southwestern Medical Center, Dallas, Texas \\ 75235-9111, and 2Department of Neurobiology, Jules Stein Eye Institute and Brain Research Institute, University of \\ California Los Angeles School of Medicine, Los Angeles, California 90095
}

\begin{abstract}
The inherited retinal dystrophies represent a large and heterogenous group of hereditary neurodegenerations, for many of which, the molecular defect has been defined. However, the mechanism of cell death has not been determined for any form of retinal degeneration. The retinal degeneration slow (rds-/-) mutation of mice is associated with nondevelopment of photoreceptor outer segments and gradual death of photoreceptor cell bodies, attributed to the absence of the outer segment protein rds/peripherin. Here, we examined the effects of a transgene encoding normal rds/peripherin that had integrated into the X-chromosome in male and female rds-/- mutant retinas. In 2-month-old transgenic males and homozygoustransgenic females on $r d s-/-$, we observed virtually complete rescue of both the outer segment nondevelopment and photoreceptor degeneration. In contrast, hemizygous-transgenic rds-/- female littermates showed patchy distributions of the
\end{abstract}

The mammalian retinal dystrophies represent a large and heterogenous subset of inherited neurodegenerations. The genetic defect for several retinal degenerations has been defined (for review, see Travis, 1998). In mice homozygous for the retinal degeneration slow $(r d s-/-)$ mutation, photoreceptor outer segments completely fail to develop (van Nie et al., 1978; Sanyal et al., 1980; Cohen, 1983). This is followed by death of the rod and cone cell bodies. The $r d s$ gene has been cloned (Travis et al., 1989), and has been shown to encode an integral membrane glycoprotein in outer segment disks named rds/peripherin (Connell et al., 1991; Travis et al., 1991). The function of rds/peripherin has not been firmly established, but indirect evidence suggests that it serves as an adhesion molecule to stabilize the rims of outer segment disks through homophilic and/or heterophilic interactions across the intradiscal space (Travis et al., 1991; Bascom et al., 1992; Goldberg et al., 1995; Goldberg and Molday, 1996; Kedzierski et al., 1996). The spontaneous $r d s$ mutation in mice results from the insertion of a repetitive genomic element into protein-coding exon II (Ma et al., 1995). Although the mutant gene is transcribed at normal levels in $r d s-/-$ mutants, no

\footnotetext{
Received Feb. 20, 1998; accepted March 20, 1998.

This work was supported by grants from the National Eye Institute and the Foundation Fighting Blindness. D.B. is the Dolly Green Professor of Ophthalmology and a Research to Prevent Blindness Senior Scientific Investigator. We gratefully acknowledge the excellent technical assistance of Marcia Lloyd, Roxana Radu, and Zifen Wang. We thank Sassan Azarian, Nathan Mata, and Izhak Nir for their valuable comments on this manuscript.

Correspondence should be addressed to Gabriel H. Travis, University of Texas Southwestern Medical Center, 5323 Harry Hines Boulevard, Dallas, TX 75235-9111. Copyright (C) 1998 Society for Neuroscience $0270-6474 / 98 / 184076-07 \$ 05.00 / 0$
}

transgene mRNA, by in situ hybridization analysis, and of photoreceptor cells that contain outer segments. This pattern is consistent with random inactivation of the X-chromosome and mosaic expression of the transgene. Surprisingly, we observed significant photoreceptor cell loss in both transgeneexpressing and nonexpressing patches in hemizygous female retinas. These observations were supported by nuclease protection analysis, which showed notably lower than predicted levels of transgene mRNA in retinas from hemizygous females compared with male and homozygous female littermates. This phenotype suggests an important component of non-cellautonomous photoreceptor death in rds-/- mutant mice. These results have significance to both the etiology and potential treatment of human inherited retinal degenerations.

Key words: retinal degeneration; retinitis pigmentosa; rds; peripherin; X-chromosome; cell autonomous; transgene

translation product can be detected (Travis et al., 1991). $r d s$ appears to be a null allele in mice (Travis et al., 1992). In humans, mutations in the $R D S$ gene are responsible for several inherited retinal dystrophies including retinitis pigmentosa (RP) (for review, see Keen and Inglehearn, 1996; Shastry, 1997).

Several years ago, we reported complete rescue of the $r d s-/-$ mutant phenotype in two transgenic mouse lines that expressed normal rds/peripherin in rod photoreceptors (Travis et al., 1992). Subsequent genetic analysis suggested that in line 113, the rescue transgene had integrated into the $\mathrm{X}$-chromosome. Inactivation of one X-chromosome occurs randomly in cells of female animals during embryogenesis (Monk and Grant, 1990; Kay et al., 1994; Moore et al., 1995). Retinas from hemizygous line 113-transgenic females (transgene present on only one X-chromosome) should therefore be mosaic for expression of the transgene. Photoreceptors derived from precursor cells in which the transgenecontaining X-chromosome was inactivated are predicted to manifest the full $r d s-/-$ phenotype, with absent outer segments and death of the cell bodies. Photoreceptors derived from precursor cells in which the transgene-containing X-chromosome is transcriptionally active should be normal. The latter case prevails with all photoreceptors in 113-transgenic males and in homozygoustransgenic females (transgene on both X-chromosomes). Here, we report the phenotype of hemizygous-transgenic female mice on an $r d s-/-$ mutant background. As predicted, we observed a mosaic pattern of transgene-expression by in situ hybridization analysis, and the patchy distribution of photoreceptor outer segments. Unexpectedly, significant photoreceptor cell loss was observed in the transgene-expressing patches of retinas from 

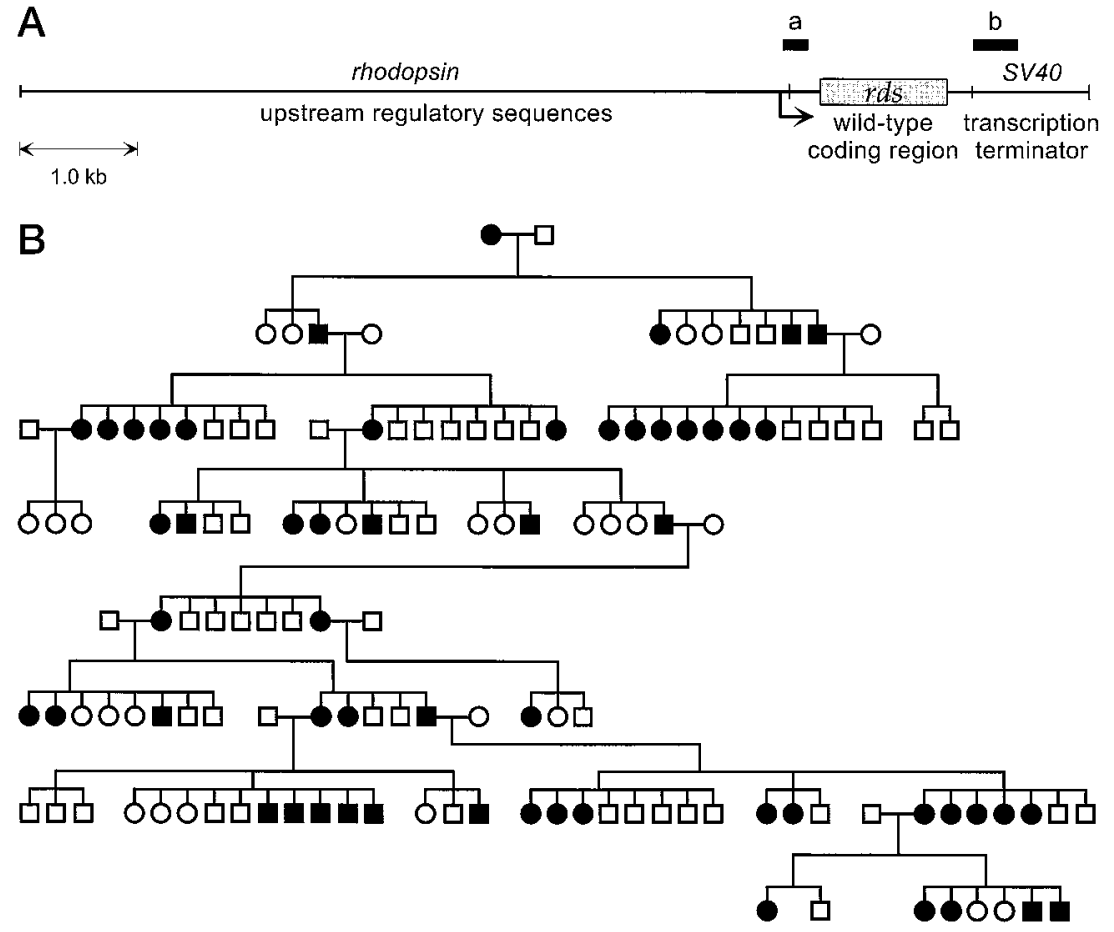

Figure 1. Line 113 wild-type $r d s$ transgene. A, Map of transgene construct; $6.5 \mathrm{~kb}$ from upstream of mouse rhodopsin gene, including 80-bp from the $5^{\prime}$-untranslated region, is fused to a wild-type $r d s$ cDNA fragment containing the complete protein-coding region. The site of transcriptional initiation is indicated by a bent arrow. The SV40 t-intron and polyadenylation signal function as a transcriptional terminator. Heavy bars show regions represented by riboprobes for nuclease protection $(a)$, and in situ hybridization analysis $(b) . B$, Pedigree showing eight generations of line 113. Squares, Males; circles, females; solid figures, transgenic; open figures, nontransgenic mice. $r d s-/-$ hemizygous females, despite virtually complete protection of these cells from degeneration in homozygous female and male littermates.

\section{MATERIALS AND METHODS}

Analysis of transgenic mice. Mice of wild-type $r d s$-transgenic line 113 were generated as described (Travis et al., 1992). The transgenic status and genetic background at $r d s$ were determined by PCR (Kedzierski et al., 1997). Homozygous and hemizygous transgenic females were distinguished by comparative PCR (Chatelain et al., 1995). All animals were tested twice using two independent tail DNA preparations, and only those of unambiguous genotype were used in further studies. In all experiments, mice were killed at $4-6 \mathrm{hr}$ after light onset (12 hr light/dark cycles).

In situ hybridization. Eyecups dissected from mice were placed in PBS, and whole retinas were collected and fixed in PBS containing $4 \%$ paraformaldehyde overnight at $4^{\circ} \mathrm{C}$. In situ hybridization was performed according to the protocol of Riddle et al. (1993) and modified by Bruhn and Cepko (1996). For the probe, digoxigenin-labeled antisense RNA was synthesized from a linearized plasmid template containing a $900 \mathrm{bp}$ SV40 fragment of the transgene construct (Fig. 1A), using T7 RNA polymerase. After overnight hybridization, signals were detected with a digoxigenin nucleic acid detection kit (Boehringer Mannheim, Indianapolis, IN), following the manufacturer's protocol. For tissue section figures, flat-mount retinas were frozen in OCT (Miles Incorporated, Kankakee, IL) after hybridization, and $10 \mu \mathrm{m}$ sections were cut, thawed onto glass slides, and photographed.

Nuclease protection analysis. Total RNA was extracted from individual eyecups using Tri Reagent (Molecular Research Center, Cincinnati, $\mathrm{OH}$ ), according to the manufacturer's protocol, and hybridized with a ${ }^{32} \mathrm{P}$-labeled antisense RNA probe of 280 nucleotides (nt), derived from the transgene construct (Fig. $1 A$, fragment $a$ ). After S1-nuclease digestion, protected fragments were analyzed by electrophoresis on an $8 \%$ polyacrylamide gel containing $8 \mathrm{~m}$ urea. Each lane contained total RNA from a single mouse retina. The probe protected a $169 \mathrm{nt}$ fragment corresponding to the endogenous $r d s$ mRNA, and a $209 \mathrm{nt}$ fragment corresponding to the transgenic mRNA (Kedzierski et al., 1997). To quantitate the protected fragments, a standard curve was prepared using in vitro-transcribed sense $r d s$ RNA. Known amounts of this RNA standard were subjected to the same treatment as total RNA. Radioactive bands corresponding to the protected fragments were quantitated on a model 425F PhosphorImager (Molecular Dynamics, Sunnyvale, CA) and compared with RNA standards on the same gel. We corrected for differences in nucleotide composition and protected fragment length in determining the absolute level of each mRNA per retina.

Light and electron microscopy. Mice were anesthetized with $50 \mathrm{mg} / \mathrm{kg}$ Nembutal (Abbott Laboratories, Santa Clara, CA) and subsequently fixed by transcardiac perfusion with formaldehyde and glutaraldehyde (1 and $2 \%$, respectively) in $0.1 \mathrm{~m}$ sodium phosphate buffer, $\mathrm{pH}$ 7.2. After the eyes were dissected, the posterior portion of each eye was cut into quadrants and fixed additionally for $1 \mathrm{hr}$ with $1 \%$ osmium tetroxide in 0.1 M sodium phosphate buffer, $\mathrm{pH}$ 7.2. The tissues were then dehydrated and embedded in Araldite 502 (Ciba Geigy, Basel, Switzerland). Sections of $0.5 \mu \mathrm{m}$ thickness were stained with toluidine blue before light microscopy. Ultrathin sections for electron microscopy were stained with uranium and lead salts.

\section{RESULTS}

\section{The line 113 rds-transgene integrated into the X-chromosome}

The transgenic construct is depicted in Figure $1 A$. This transgene gives rod-specific expression of a mRNA encoding normal rds/ peripherin at a similar level to that of the endogenous $r d s$ mRNA (Travis et al., 1992). A pedigree showing several generations of mice from transgenic line 113 is shown in Figure $1 B$. Note that males always transmit the transgene to their female but never their male offspring, whereas hemizygous females transmit to both male and female offspring. This pattern of inheritance is only consistent with integration of the transgene into the $\mathrm{X}$-chromosome.

\section{Mosaic expression of the transgene in retinas from hemizygous females}

We performed in situ hybridization analysis on whole-mount retinas from 1-month-old mice of different genotypes using an antisense SV40 riboprobe (Fig. $1 A$, fragment $b$ ). Uniform labeling was observed across the entire retina in transgenic male and homozygous-transgenic female mice (Fig. 2B,D). Patchy labeling was observed in retinas from female hemizygous-transgenic mice (Fig. $2 C$ ). No labeling was observed in retinas from nontransgenic C57BL/6 mice (Fig. 2A). After hybridization, the retinas were cut 

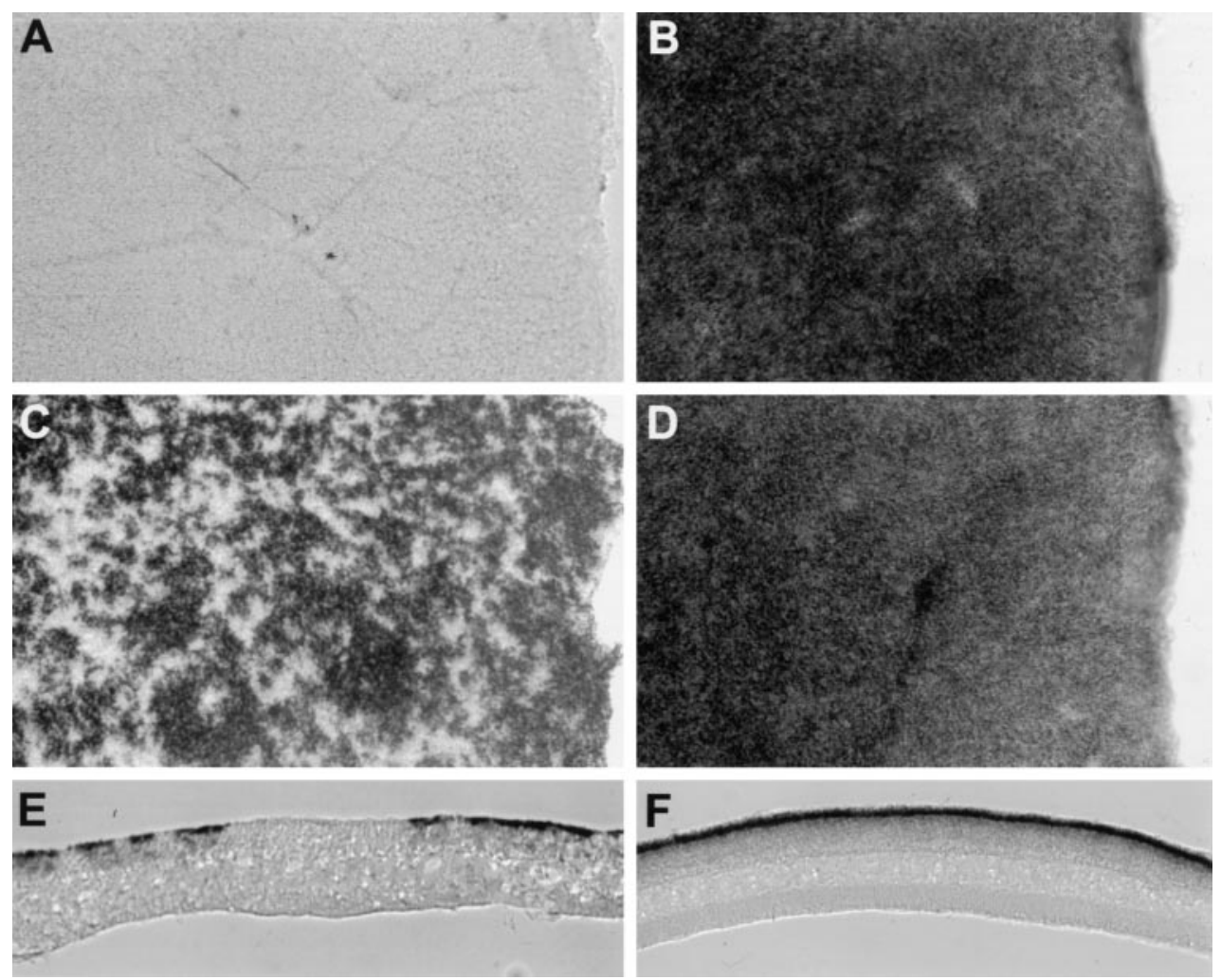

Figure 2. In situ hybridization analysis of retinas from 1-month-old mice using a digoxigenin-labeled riboprobe complementary to SV40 in the transgene. $A$, Whole mount of a retina from a nontransgenic C57BL/6 mouse. $B$, Whole mount of a retina from a male transgenic mouse on $r d s-/-$ genetic background. $C$, Whole mount of a retina from a female transgenic hemizygote on $r d s-/-. D$, Whole mount of a retina from a female transgenic homozygote on $r d s-/-$. Sections encompassing $\sim 20 \%$ of one retinal diameter are represented in plates $A-D$. A retinal edge is included in each plate to show the photographic background intensity. Note the patchy distribution of hybridization signal in $C$. E, Full-thickness section of retina from female transgenic hemizygote on $r d s-/-. F$, Full-thickness section of retina from female transgenic homozygote on $r d s-/-$. Note the interrupted hybridization signal in the photoreceptor cell layer in $E$ compared with $F$. Magnification: $A-D, 70 \times ; E, F, 120 \times$.

into $10 \mu \mathrm{m}$ sections. Patchy labeling was observed in the outer retinal (photoreceptor cell) layer of hemizygous transgenics, whereas homozygous females showed uniform labeling of the photoreceptor cell layer (Fig. 2E,F).

\section{Expression of endogenous and transgenic rds mRNAs}

Nuclease protection analysis was done on individual retinal samples from mice of different genotypes at $12 \mathrm{~d}$ and 2 months using a riboprobe that distinguished the transgenic from the endogenous $r d s$ mRNAs (Fig. 3). The absolute level of each RNA species per retina was determined in six mice of each genotype (Table 1). We observed the approximate doubling of RNA levels in mice of comparable genotypes between $12 \mathrm{~d}$ and 2 months, presumably because of retinal growth and maturation. The level of the transgene mRNA in 12-d-old female homozygotes on an $r d s-/-$ background was approximately equal to that of male transgenic littermates and approximately twice that of female transgenic hemizygotes. By 2 months, the level of the transgenic mRNA in female hemizygotes was only $26 \%$ that of male littermates, suggesting loss of transgene-expressing photoreceptors in female hemizygotes.

\section{Numbers of photoreceptors are similar in young transgenic male and hemizygous transgenic female mice}

We examined retinas from 12-d-old transgenic male and hemizygous-transgenic female littermates on the $r d s-/-$ genetic background (Fig. 4). Outer segments were shorter and less orga- nized than those of transgenic male littermates. Significantly, outer nuclear layer thickness at $12 \mathrm{~d}$ was identical in hemizygoustransgenic females and transgenic males and comparable to that of nontransgenic wild-type controls (data not shown). This result suggests that hemizygous transgenic females begin with a similar number of photoreceptor cells as their male counterparts.

\section{Patchy outer segment dysplasia and photoreceptor degeneration in hemizygous-transgenic females}

By light microscopic analysis, outer nuclear layer thickness and outer segment appearance were virtually indistinguishable in retinas from transgenic male and homozygous-transgenic female mice on $r d s-/-$ and nontransgenic wild-type mice, all at 2 months of age (Fig. $5 A-C$ ). In contrast, retinas from hemizygoustransgenic female littermates showed a discontinuous pattern of photoreceptor patches that contain or lacked outer segments (Fig. $5 D$ ). The outer nuclear layer was uniformly thinner in these females, with five or six rows of photoreceptor nuclei, suggesting significant photoreceptor degeneration. Retinas from 2-monthold nontransgenic $r d s-/-$ mutant mice contained four or five rows of photoreceptor nuclei with absent outer segments throughout (Fig. 5E). Electron microscopic analysis of retinas from 2 month hemizygous-transgenic $r d s-/-$ female mice showed patches of photoreceptors containing outer segments adjacent to patches of photoreceptors that completely lack outer segments (Fig. 6). The outer segments were well organized but somewhat shortened compared with wild type. 
A
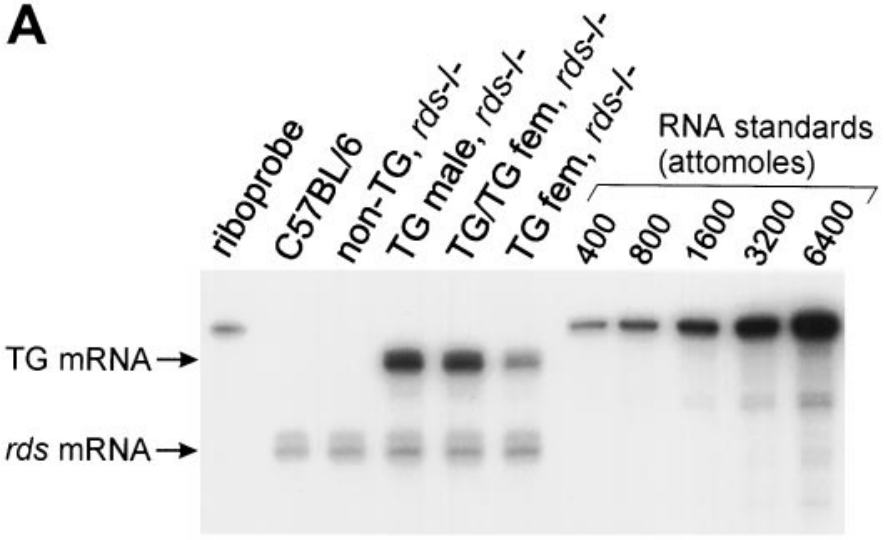

12 days

B

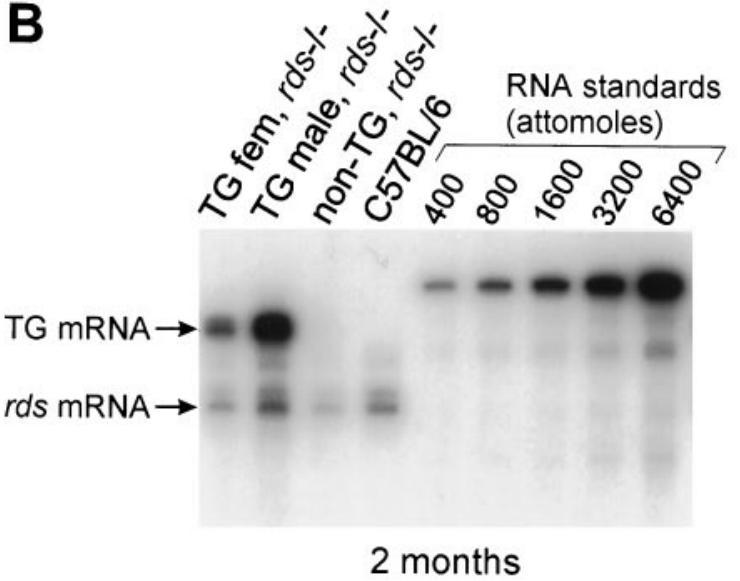

Figure 3. Nuclease protection analysis of retinal RNA. An antisense $r d s$ riboprobe (280-nt) was used to protect a $209 \mathrm{nt}$ fragment of the transgene mRNA and a $169 \mathrm{nt}$ fragment of the wild-type or mutant endogenous $r d s$ mRNA. $A$, Representative lanes from 12-d-old mice of the indicated genotypes. Transgenic hemizygotes are indicated by $T G$, and homozygote is indicated by $T G / T G$. B, Representative lanes from 2-month-old mice of the indicated genotypes. A series of five quantitation standards containing from 400 to 6400 attomoles of RNA are shown to the right of each gel.

\section{DISCUSSION}

Based on the results of retroviral tagging studies, the vertebrate retina is thought to develop from a germinal epithelial layer, in which individual progenitor cells give rise to all classes of neurons within a radial column (Turner and Cepko, 1987; Holt et al., 1988; Fields-Berry et al., 1992). Recently, a line of transgenic
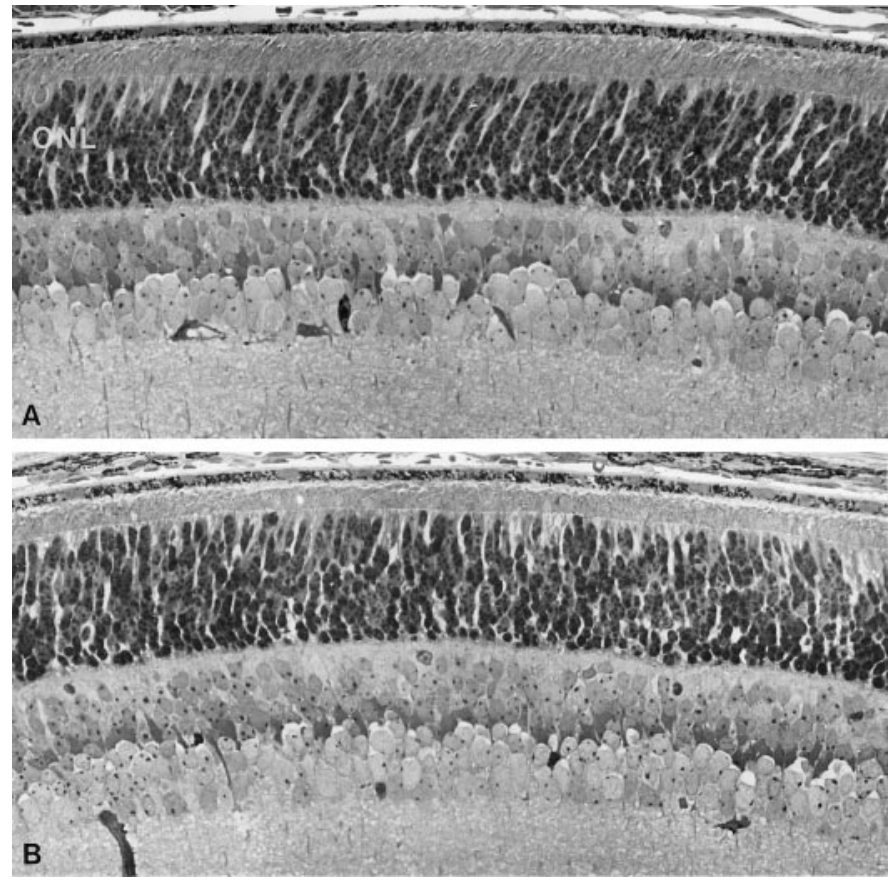

Figure 4. Light micrographs of retinal sections from predegenerate transgenic mice. A, Retina from 12-d-old transgenic male on $r d s-/-$ background. $B$, Retina from 12-d-old hemizygous-transgenic female on $r d s-/-$ background. Note the similar thickness of outer nuclear layers (ONL) (dark stained nuclei) in both sections. Magnification, 490×.

mice was described containing a ubiquitously expressed lac $Z$ reporter gene that had integrated into the $\mathrm{X}$-chromosome (Reese et al., 1995). When female retinas from this line were stained with $\mathrm{X}$-gal, a fine mosaic pattern of radially arranged blue and white columns was revealed. Virtually no lateral dispersion of bluestained photoreceptors into nonstained patches was seen. These observations suggest that during development, minimal intermingling occurs between photoreceptors derived from distinct clonal precursor cells.

We observed two morphological patterns of mosaicism in retinas from line 113 hemizygous-transgenic females on an $r d s-/-$ mutant background. First, patchy expression of the transgene was seen in photoreceptors by in situ hybridization. Male and homozygous female littermates, in contrast, showed uniform expression of the transgene. Second, we observed a patchy distribution of photoreceptors containing outer segments in hemizygoustransgenic female retinas. The size of these patches varied in

Table 1. Absolute levels of $r d s$ mRNAs in attomoles per retina

\begin{tabular}{|c|c|c|c|c|}
\hline \multirow[b]{2}{*}{ Genotype } & \multicolumn{2}{|l|}{$12 \mathrm{~d}$} & \multicolumn{2}{|l|}{2 months } \\
\hline & $\begin{array}{l}\text { Wild-type or mutant } \\
\text { endogenous mRNA }\end{array}$ & Transgenic mRNA & $\begin{array}{l}\text { Wild-type or mutant } \\
\text { endogenous mRNA }\end{array}$ & Transgenic \\
\hline C57BL/6 & $433 \pm 55$ & ND & $960 \pm 70$ & ND \\
\hline Non-TG, $r d s-/-$ & $556 \pm 49$ & ND & $233 \pm 8$ & ND \\
\hline TG male, $r d s-/-$ & $635 \pm 53$ & $1996 \pm 107$ & $1036 \pm 40$ & $4853 \pm 203$ \\
\hline TG female, $r d s-/-$ & $598 \pm 51$ & $844 \pm 114$ & $410 \pm 66$ & $1280 \pm 290$ \\
\hline TG/TG female; $r d s-/-$ & $673 \pm 34$ & $1953 \pm 70$ & - & - \\
\hline
\end{tabular}

Retinas were prepared from mice of the indicated ages and genotypes and submitted to nuclease protection analysis. The autoradiographic signal intensities were measured in six retinas for wild-type or mutant endogenous and transgenic mRNAs and compared with standard curves as shown in Figure 3. Displayed values were corrected for riboprobe length and nucleotide composition and shown \pm SEM. TG, Transgenic; TG/TG, homozygous-transgenic; ND, no signal detected; dash, assay not performed. 

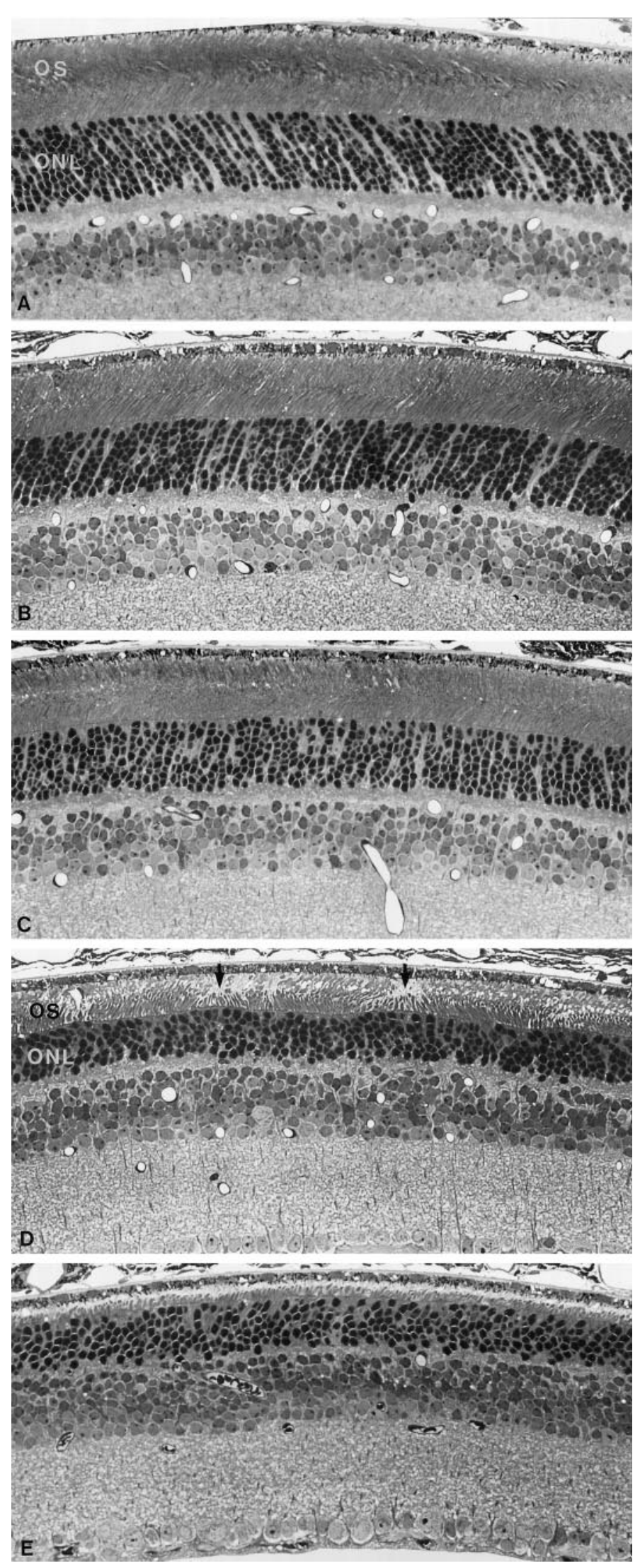

Figure 5. Light micrographs of retinal sections from 2-month-old mice of several genotypes. $A$, Nontransgenic C57BL/6 wild-type. $B$, Transgenic male on $r d s-/-$. $C$, Homozygous-transgenic female on $r d s-1-$. $D$, Hemizygous-transgenic female on $r d s-1-$. E, Nontransgenic male $r d s-1-$ width from several cell diameters to $>50$. The observed mosaic pattern of transgene expression in these females is likely attributed to random inactivation of the transgene-bearing $\mathrm{X}$-chromosome. $\mathrm{X}$ inactivation has been shown to occur between 5.5 and $10.5 \mathrm{~d}$ after conception in different tissues of the mouse embryo (Tan et al., 1993). The precise time of X inactivation in the developing optic vesicle has not been determined. The fine pattern of retinal mosaicism observed by us and others (Reese et al., 1995) suggests that $X$ inactivation occurs late within this time window in retinal precursor cells.

An unexpected finding in the current study was that both transgene-expressing and nonexpressing photoreceptors undergo degeneration in hemizygous-transgenic females on the $r d s-/-$ genetic background. This conclusion was based on several observations. If transgene-expressing photoreceptors in $r d s-/-$ female retinas were protected from degeneration, as they are in males and homozygous females, we would have expected outer nuclear layers of irregular width, with $\sim 10$ rows of nuclei in patches of photoreceptors that contain outer segments, and four or five rows in non-transgene-expressing patches (Sanyal et al., 1980). Instead, we observed uniform thinning of outer nuclear layers across transgene-expressing and nonexpressing patches. Could this observation be explained by the lateral migration of transgeneexpressing "rescued" photoreceptors into nonexpressing patches? Although some lateral migration may occur, the number of photoreceptors in hemizygous-female retinas is significantly fewer than can be accounted for by this explanation. The outer nuclear layer width in 2-month-old hemizygous female retinas (five or six rows) was nearly the same as in nontransgenic $r d s-/-$ littermates (four or five rows). If the observed uniformity of outer nuclear layer width was attributed only to lateral migration of transgeneexpressing photoreceptors, we would have expected an overall thickness of about seven rows in these females. Furthermore, by nuclease protection analysis, the absolute level of transgene mRNA in hemizygous female retinas was approximately half that of both transgenic males and homozygous-transgenic females at $12 \mathrm{~d}$. However, by 2 months, the level of the transgene mRNA in hemizygous females dropped to approximately one-fourth that of the male littermates. If transgene-expressing photoreceptors were protected from cell death in hemizygous females, as they are in males and homozygous females, we would have expected a female-to-male expression ratio of $\sim 50 \%$ at both $12 \mathrm{~d}$ and 2 months. Collectively, these data suggest that the transgeneexpressing photoreceptors are dying at a much higher rate in hemizygous female retinas compared with males and homozygous females on the same $r d s-/-$ genetic background.

We observed accumulations of vesicular debris in the subretinal space (between photoreceptors and cells of the pigment epithelium) in nonrescued patches of hemizygous-transgenic female retinas (Fig. 6). Similar vesicles have been observed in the subretinal space of nonmosaic $r d s-/-$ mutant mice (Jansen and Sanyal, 1984). These vesicles react strongly with antibodies against rhodopsin (Nir and Papermaster, 1986; Jansen et al., 1987; Usukura and Bok, 1987), suggesting that they are composed of membrane destined to form outer segments, which failed to form

mutant. Arrows in $D$ indicate patches of photoreceptors that lack outer segments. Note the normal appearance of outer segments (OS) and similar thickness of outer nuclear layers in $A-C$. Also note the similar reductions in outer nuclear layer-thickness in $D$ and $E$. Outer segments are completely lacking in $E$. Magnification, $490 \times$. 


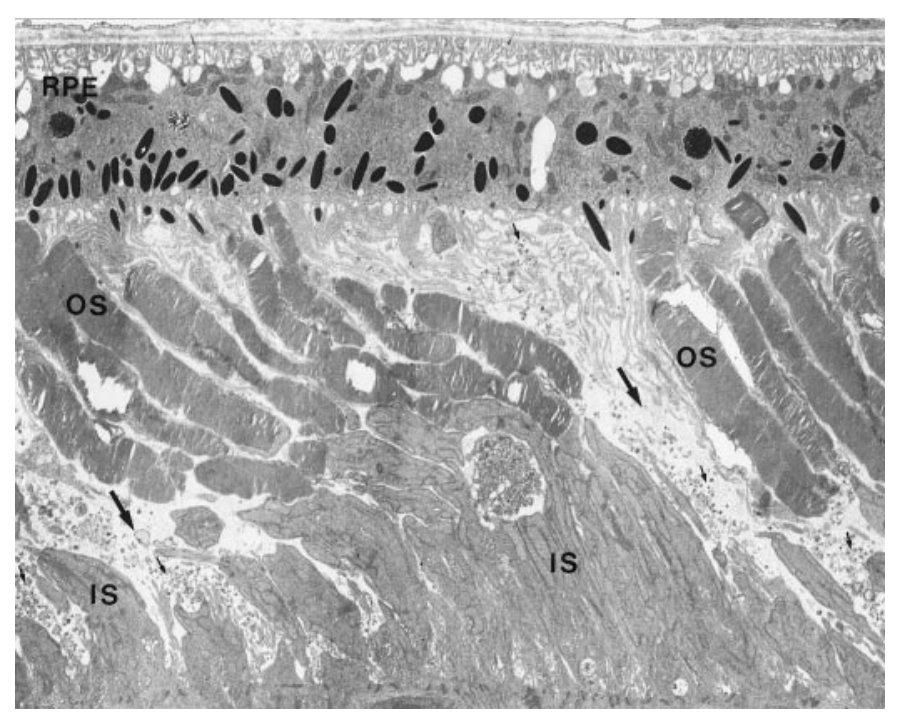

Figure 6. Electron micrograph of a distal retina from a 2-month-old hemizygous-transgenic female $r d s-/-$ mouse. Shown is a region containing small patches of photoreceptors that contain and lack outer segments. Photoreceptor inner segments (IS), outer segments $(O S)$, and retinal pigment epithelium (RPE) are labeled. Note the absence of outer segments $(O S)$ in the nonexpressing patches (large arrows) and the presence of vesicular debris (small arrows). Magnification, 5500×.

disks because of the absence of rds/peripherin. These vesicles do not accumulate with age in $r d s-/-$ mice, implying that they are cleared by the pigment epithelium, as are shed outer segments in normal retina. A possible explanation for the observed accumulation of vesicles in female mosaic retinas is that neighboring outer segments in transgene-expressing patches confer a "tent pole" effect, physically separating the pigment epithelial cells from the photoreceptor ciliary processes, and thus slowing phagocytosis. Although the organization of outer segments in the transgene-expressing photoreceptors is normal, these structures are somewhat shorter than those observed in wild-type retinas or retinas from transgenic $r d s-/-$ males. Because addition of outer segment disks is a continuous process in adult photoreceptors (Young and Bok, 1969), representing a significant metabolic burden to the cell, the shortening of outer segments within the transgene-expressing patches may be an early sign of reduced photoreceptor viability.

A possible explanation for the death of transgene-expressing cells is that degenerating photoreceptors release a toxic factor or factors that trigger apoptosis in neighboring cells. In $r d s-/-$ mutants, $40 \%$ of photoreceptors are lost during the first month (Nir et al., 1990). This is followed by more gradual loss of the remaining photoreceptors over months to years, depending on the background strain (Sanyal et al., 1980). This rapid phase of degeneration may reflect a positive feedback between the cellautonomous and nonautonomous effects, resulting in accelerated release of toxic factors by the dying cells. Cells "left standing" after the initial devastation may die more slowly because of reduced generation of these toxic factors. Several other observations support this model. Sanyal and Zeilmaker, (1984) described retinal morphologies in wild-type $\leftrightarrow r d s-/-$ aggregation chimeras. Although quantitative analysis of retinal degeneration was not done in these mice, a reduction in the number of photoreceptor nuclei to a level intermediate between that of wild-type and $r d s-/-$ mutant retinas was observed. Also, aggregation chi- meras were generated between wild-type and transgenic mice carrying the dominant RP-associated P347S mutation in a pig rhodopsin gene (Huang et al., 1993). Here, the authors observed uniform reductions in the number of photoreceptor nuclei across both transgenic and nontransgenic patches, again suggesting a non-cell-autonomous mechanism of photoreceptor death.

An alternative explanation for non-cell-autonomous photoreceptor loss is that viable photoreceptors confer a trophic effect on one another. In the wild-type $\leftrightarrow$ P347S chimeras reported by Huang et al. (1993), the rate of photoreceptor cell loss was correlated with degree of transgenic chimerism. As the authors proposed, this result suggests a protective effect of wild-type cells on cells expressing the mutant transgene. Thus, non-cellautonomous photoreceptor death in hemizygous females may be attributable, at least in part, to loss of a trophic effect required for photoreceptor survival.

Humans are affected by a heterogenous group of inherited retinal degenerations, typified by RP. Multiple genes have been implicated in RP, most of which are expressed specifically in rod but not cone photoreceptors (for review, see Travis, 1998). However, RP is invariably associated with the death of both rod and cone photoreceptor cells (Heckenlively, 1988). Cone cell degeneration in RP caused by mutations in rod-specific genes may represent still another instance of non-cell-autonomous photoreceptor death. Finally, in X-linked RP, a significant fraction of human female "carriers" are reported to have visual abnormalities (Bird, 1975; Rusin et al., 1989; Friedrich et al., 1993; Stavrou et al., 1996). By definition, these carriers are mosaic for expression of the mutant X-linked RP allele. The mechanism of visual loss in X-linked RP carriers has never been defined. This disease process may be similar to what we observe in retinas from hemizygous-transgenic female $r d s-/-$ mutants. Thus, in several disparate systems, photoreceptor degeneration appears to be mediated by a combination of cell-autonomous and non-cellautonomous effects. A common cellular process may underlie these different examples of photoreceptor degeneration.

In summary, we have characterized the effects on retina of a wild-type $r d s$ transgene that integrated into the X-chromosome. When placed on an $r d s-/-$ genetic background, this transgene resulted in mosaic rescue of the outer segment phenotype in hemizygous females. Significant photoreceptor cell loss was observed in both transgene-expressing and nonexpressing retinal patches. This observation suggests the existence of a major noncell-autonomous component to photoreceptor degeneration in $r d s-/-$ mutants. A similar process may be operative in other mammalian retinal degenerations, including RP in humans. It may also explain the high prevalence of visual abnormalities in female carriers of X-linked RP. Finally, because photoreceptors are a subtype of neurons, non-cell-autonomous degeneration may occur in other neurodegenerative disorders, including those not involving inflammation. If true, this has important therapeutic ramifications. Identifying the putative extracellular signal(s) that trigger apoptosis in neighboring neurons could lead to the development of pharmaceutical agents that may slow progression of these diseases. The line 113 transgenic mouse would be a useful animal model to test the efficacy of these potential treatments on the non-cell-autonomous component of neuronal degeneration.

\section{REFERENCES}

Bascom RA, Garcia-Heras J, Hsieh CL, Gerhard DS, Jones C, Francke U, Willard HF, Ledbetter DH, McInnes RR (1992) Localization of the photoreceptor gene ROM1 to human chromosome 11 and mouse 
chromosome 19: sublocalization to human 11q13 between PGA and PYGM. Am J Hum Genet 51:1028-1035.

Bird AC (1975) X-linked retinitis pigmentosa. $\mathrm{Br} \mathrm{J}$ Ophthalmol 59:177-199.

Bruhn SL, Cepko CL (1996) Development of the pattern of photoreceptors in the chick retina. J Neurosci 16:1430-1439.

Chatelain G, Brun G, Michel D (1995) Screening of homozygous transgenic mice by comparative PCR. Biotechniques 18:958-962.

Cohen AI (1983) Some cytological and initial biochemical observations on photoreceptors in retinas of rds mice. Invest Ophthalmol Vis Sci 24:832-843.

Connell G, Bascom R, Molday L, Reid D, McInnes RR, Molday RS (1991) Photoreceptor peripherin is the normal product of the gene responsible for retinal degeneration in the $r d s$ mouse. Proc Natl Acad Sci USA 88:723-726.

Fields-Berry SC, Halliday AL, Cepko CL (1992) A recombinant retrovirus encoding alkaline phosphatase confirms clonal boundary assignment in lineage analysis of murine retina. Proc Natl Acad Sci USA 89:693-697.

Friedrich U, Warburg M, Jorgensen AL (1993) X-inactivation pattern in carriers of $\mathrm{X}$-linked retinitis pigmentosa: a valuable means of prognostic evaluation? Hum Genet 92:359-363.

Goldberg AF, Molday RS (1996) Subunit composition of the peripherin/ rds-rom-1 disk rim complex from rod photoreceptors: hydrodynamic evidence for a tetrameric quaternary structure. Biochemistry 35:6144-6149.

Goldberg AF, Moritz OL, Molday RS (1995) Heterologous expression of photoreceptor peripherin/rds and Rom-1 in COS-1 cells: assembly, interactions, and localization of multisubunit complexes. Biochemistry 34:14213-14219.

Heckenlively JR (1988) Retinitis pigmentosa syndromes. In: Retinitis pigmentosa (Heckenlively JR, ed), pp 221-252. Philadelphia: Lippincott.

Holt CE, Bertsch TW, Ellis HM, Harris WA (1988) Cellular determination in the Xenopus retina is independent of lineage and birth date. Neuron 1:15-26.

Huang PC, Gaitan AE, Hao Y, Petters RM, Wong F (1993) Cellular interactions implicated in the mechanism of photoreceptor degeneration in transgenic mice expressing a mutant rhodopsin gene. Proc Natl Acad Sci USA 90:8484-8488.

Jansen HG, Sanyal S (1984) Development and degeneration of retina in $r d s$ mutant mice: electron microscopy. J Comp Neurol 224:71-84.

Jansen HG, Sanyal S, De Grip WJ, Schalken JJ (1987) Development and degeneration of retina in $r d s$ mutant mice: ultraimmunohistochemical localization of opsin. Exp Eye Res 44:347-361.

Kay GF, Barton SC, Surani MA, Rastan S (1994) Imprinting and $\mathrm{X}$-chromosome counting mechanisms determine $\mathrm{X}$ ist expression in early mouse development. Cell 77:639-650.

Kedzierski W, Moghrabi WN, Allen AC, Jablonski-Stiemke M, Bok D, Travis GH (1996) Three homologs of rds/peripherin in Xenopus laevis photoreceptors that exhibit covalent and noncovalent interactions. J Cell Sci 109:2551-2560.

Kedzierski W, LLoyd M, Birch DG, Bok D, Travis GH (1997) Generation and analysis of transgenic mice expressing P216L-substituted rds/peripherin in rod photoreceptors. Invest Ophthalmol Vis Sci 38:498-509.

Keen TJ, Inglehearn CF (1996) Mutations and polymorphisms in the human peripherin-rds gene and their involvement in inherited retinal degeneration. Hum Mutat 8:297-303.
Ma J, Norton JC, Allen AC, Burns JB, Hasel KW, Burns JL, Sutcliffe JG, Travis GH (1995) Retinal degeneration slow $(r d s)$ in mouse results from simple insertion of a $\mathrm{t}$ haplotype-specific element into proteincoding exon II. Genomics 28:212-219.

Monk M, Grant M (1990) Preferential X-chromosome inactivation, DNA methylation and imprinting. Dev Suppl 55-62.

Moore T, Hurst LD, Reik W (1995) Genetic conflict and evolution of mammalian X-chromosome inactivation. Dev Genet 17:206-211.

Nir I, Papermaster DS (1986) Immunocytochemical localization of opsin in the inner segment and ciliary plasma membrane of photoreceptors in retinas of rds mutant mice. Invest Ophthalmol Vis Sci 27:836-840.

Nir I, Agarwal N, Papermaster DS (1990) Opsin gene expression during early and late phases of retinal degeneration in rds mice. Exp Eye Res 51:257-267.

Reese BE, Harvey AR, Tan SS (1995) Radial and tangential dispersion patterns in the mouse retina are cell-class specific. Proc Natl Acad Sci USA 92:2494-2498.

Riddle RD, Johnson RL, Laufer E, Tabin C (1993) Sonic hedgehog mediates the polarizing activity of the ZPA. Cell 75:1401-1416.

Rusin MM, Fishman GA, Larson JA, Gilbert LD (1989) Vitreous fluorophotometry in carriers of choroideremia and $\mathrm{X}$-linked retinitis pigmentosa. Arch Ophthalmol 107:209-212.

Sanyal S, Zeilmaker GH (1984) Development and degeneration of retina in $r d s$ mutant mice: light and electron microscopic observations in experimental chimaeras. Exp Eye Res 39:231-246.

Sanyal S, De Ruiter A, Hawkins RK (1980) Development and degeneration of retina in $r d s$ mutant mice: light microscopy. J Comp Neurol 194:193-207.

Shastry BS (1997) Signal transduction in the retina and inherited retinopathies. Cell Mol Life Sci 53:419-429.

Stavrou P, Good PA, Broadhurst EJ, Bundey S, Fielder AR, Crews SJ (1996) ERG and EOG abnormalities in carriers of X-linked retinitis pigmentosa. Eye 10:581-589.

Tan SS, Williams EA, Tam PPL (1993) X-chromosome inactivation occurs at different times in different tissues of the postimplantation mouse embryo. Nat Genet 3:170-174.

Travis GH (1998) Mechanisms of cell death in the inherited retinal degenerations. Am J Hum Genet 62:503-508.

Travis GH, Brennan MB, Danielson PE, Kozak CA, Sutcliffe JG (1989) Identification of a photoreceptor-specific mRNA encoded by the gene responsible for retinal degeneration slow $(r d s)$. Nature 338:70-73.

Travis GH, Sutcliffe JG, Bok D (1991) The retinal degeneration slow $(r d s)$ gene product is a photoreceptor disc membrane-associated glycoprotein. Neuron 6:61-70.

Travis GH, Groshan KR, Lloyd M, Bok D (1992) Complete rescue of photoreceptor dysplasia and degeneration in transgenic retinal degeneration slow $(r d s)$ mice. Neuron 9:113-119.

Turner DL, Cepko CL (1987) A common progenitor for neurons and glia persists in rat retina late in development. Nature 328:131-136.

Usukura J, Bok D (1987) Changes in the localization and content of opsin during retinal development in the $r d s$ mutant mouse: immunocytochemistry and immunoassay. Exp Eye Res 45:501-515.

van Nie R, Ivanyi D, Demant P (1978) A new H-2 linked mutation, $r d s$, causing retinal degeneration in the mouse. Tissue Antigens 12:106-108.

Young RW, Bok D (1969) Participation of the retinal pigment epithelium in the rod outer segment renewal process. J Cell Biol 42:392-403. 